\title{
The Influence of Ultrasonic Stirring on the Solidification Microstructure and Mechanical Properties of A356 Alloy
}

\author{
S. Jia, L. Nastac* \\ The University of Alabama, Department of Metallurgical and Materials Engineering, \\ Box 870202, Tuscaloosa, Alabama, 35487, United States \\ *Corresponding Author: lnastac@eng.ua.edu
}

Copyright $(2013$ Horizon Research Publishing All rights reserved.

\begin{abstract}
Ultrasonic treatment has significant effects on the solidified microstructure, which includes grain structure, distribution of inclusions, refinement of secondary phases, etc. The primary causes are due to ultrasonic cavitation, acoustic streaming and movement of dislocations associated with propagation of ultrasound waves in media. However, the mechanism of how those effects happen are not fully understood and quantified. In this research, molten A356 alloy was treated with high power ultrasound at a frequency of $18 \mathrm{kHz}$, and then at relatively high superheat, the melt was cast into a permanent metal mold which complies with ASTM B108-02. The relatively high superheat condition is similar to one used in the standard foundry practice. The selected parameters for the ultrasonic stirring technology (UST) were determined by using a UST model that was recently developed and validated. The ultrasonically-stirred A356 alloy shows superior microstructure characteristics with very low micro-porosity levels. The microstructure and mechanical properties of the A356 alloy processed with and without UST were analyzed and compared in detail in this paper.
\end{abstract}

Keywords Ultrasonic Processing, Ultrasonic Cavitation and Acoustic Streaming, Aluminum Alloys, Microstructure, Mechanical Properties

\section{Introduction}

The earliest research of ultrasonic stirring effect on metal can date back to 1878 , when Chernov [1] was trying to improve the quality of cast metal by elastic oscillations. Since then, a large amount of relevant research [2-16] has been made in this field. It has been proved experimentally that UST treatment into melt metal can eliminate columnar dendritic structure, may obtain globular non-dendritic structures, and more refined microstructure2. Cast components with globular grains have many advantages including the decrease of hot tearing susceptibility, isotropic microstructure and properties, reduced micro-segregation due to reduced grain size, improved resistance to corrosion, and improvement of mechanical properties, such as hardness, yield strength, and elongation 3 .

The main objective of this study is to determine the dominant mechanism for UST grain refinement and the key parameters of the UST experiments. Also, under relatively high superheat condition, analysis on the as-cast microstructure in conjunction with relatively low (e.g., silica sand molds) and high (e.g., permanent molds) cooling rates will assist the manufacturing industry in the scale up of the ultrasonic technology for commercial applications.

UST can apply high intensity of acoustic energy into the melt. As described in Fig. 1, the application of ultrasonic energy to the melt causes instantaneous local pressure oscillation. During cavitation, low pressure creates tiny bubbles while high pressure makes the bubbles collapse and produce shock waves. During the solidification of castings, UST can be used for degassing and microstructure refinement and modification. The main effects of the UST processing are discussed below:

(1) UST induced degassing: During the cavitation process, very small bubbles are created at low pressure. These bubbles can act as nuclei for the formation of hydrogen and vapor bubbles. Hydrogen will escape from the liquid. The degassing efficiency is proportional to the ultrasonic intensity.

(2) Grain nucleation: There are several ways that UST can alter grain nucleation. Since the pressure oscillations exist in a melt under UST processing, the liquidus temperature for the melt is changed. Thus, some part of the melt is superheated and the other part is undercooled. This phenomenon occurs at high frequencies and causes increase in the amount of nuclei into the melt [18-20].

(3) Dendrite fragmentation: Dendrites usually starts melting at the root due to local temperature rise and segregation. In the melt, UST produces strong convection and shock waves which may promote dendrite fragmentation. Convection can promote dendrite fragmentation because it causes local temperature and composition variations and promotes 
diffusion of solute. Shock waves will induce the breakage of the melting root $[21,22]$.

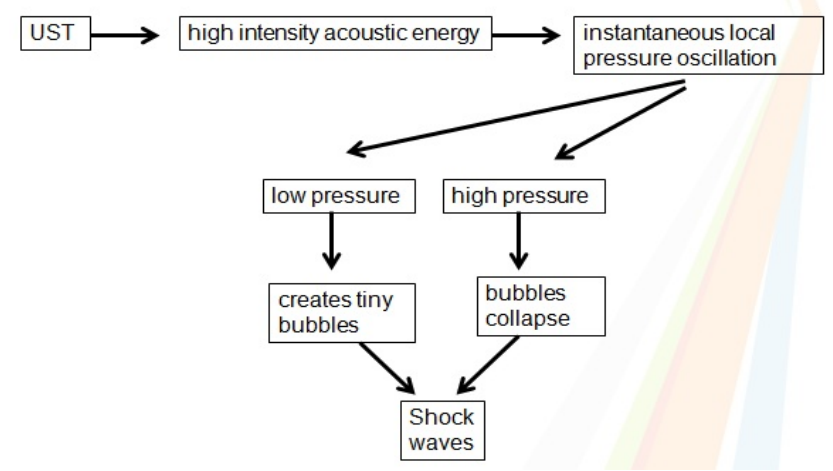

Figure 1. Phenomena occurring in the melt during the UST processing

The mechanisms for UST induced grain refinement are related to pressure and temperature oscillations in the melt. As discussed above, these oscillations are likely to induce heterogeneous nucleation in the melt. In addition, they are probably enhancing dendrite fragmentation. However, the dominant mechanism for grain refinement has not been determined yet. More related experiments need to be performed to understand which mechanism is dominant $[4$, 5].

There have been many different views regarding the mechanisms of ultrasonic grain refinement. Generally these mechanisms can be classified into two groups due to the absence and presence of cavitation. In the first group, they share the same assumption that grain refinement is induced by ultrasonic under the frequency below the cavitation threshold. In this group, there are also two different views. Chernov [1] hold the view that a strong stirring effect exists in the melt because of the UST. The strong stirring effect will significantly increase the heat transfer from the melt to the environment, thus the melt is cooled down and the nucleation is enhanced. This stirring effect can be achieved by mechanical stirring and other methods. By measuring the temperature in the melt, the cooling down of the melt can be observed.

Abramov developed with a new theory [11]. By using UST under a frequency below the cavitation threshold, Abramov conducted some experiments to disperse organic and metallic crystals. It was observed that the UST under the frequency below the cavitation threshold had no significant effect on the solidification front; only the temperature distribution in the melt had been changed. By using the UST treatment of the melt, a wide two-phase zone is formed to promote grain refinement, even in the absence of cavitation in the melt. The refinement is affected by $\mathrm{G} / \mathrm{V}$ ratio $(\mathrm{G}$ is the temperature gradient and $\mathrm{V}$ is the solidification rate). Increasing the temperature gradient and decreasing the solidification rate would cause less grain refinement. Abramov explains that the ultrasonic treatment using a frequency below the cavitation threshold may result in pressure oscillations, viscous friction forces and dynamic forces, which promote the grain refinement.

In the second group, one explanation for cavitation-aided grain refinement is about shock waves. UST causes pressure oscillations. Low pressure produces tiny bubbles. When the bubbles collapse, powerful shock waves are generated. It is believed that shock waves occurring near the solidification front cause dendrite fragmentation. Thus dendrite fragments may act as nucleation sites $[10,12]$.

This opinion also assumed that cavitation can activate inclusions in the melt to turn to nucleation sites. Those inclusions are usually unwettable by metal melt, but under the UST treatment, bubbles may form on those inclusion particles which make them to be wettable.

Another mechanism of grain refinement in the presence of cavitation was proposed by Chalmers [17]. The pressure increase leads to rise of solidification temperature, which promotes nucleation in the melt. Assuming that the local pressure will rise to $100-1000 \mathrm{MPa}$, the melting point of aluminum can temporarily increase by more than ten degrees. Thus, the undercooling in the melt can be increased enough to enhance nucleation.

The other mechanism proposed is by Hem [19]. During the expansion process, the bubbles size increase rapidly. At the same time, the liquid evaporates inside the bubble. The expansion and vaporization will reduce the bubble temperature. As long as the temperature keeps falling down below the solidification temperature, certain amount of undercooling is formed to enhance the nucleation on the bubbles.

Although large amount of efforts has been put in the field of ultrasonic processing of metal, the mechanism of UST induced grain refinement has not been determined yet. This means that additional experimental work still need to be performed to clearly understand which mechanism is dominant for UST induced grain refinement.

\section{Experimental Approach}

A sketch of the UST treatment equipment is presented in Fig. 2(a). The setup consists of an $18 \mathrm{kHz} 4 \mathrm{~kW}$ ultrasonic generator, a transducer, a cylindrical $\mathrm{Nb}$ probe $(40 \mathrm{~mm}$ diameter), a control panel (for power and frequency adjustments) and an induction furnace that is used to melt the A356 alloy (Table 1). The position of the ultrasonic probe can be adjustable. The melt temperature is measured by a K-type thermocouple.

Table 1. Nominal chemical composition of matrix alloy A356

\begin{tabular}{|c|c|c|c|c|c|c|c|c|}
\hline Elem. & $\mathrm{Si}$ & $\mathrm{Fe}$ & $\mathrm{Cu}$ & $\mathrm{Mn}$ & $\mathrm{Mg}$ & $\mathrm{Zn}$ & $\mathrm{Ti}$ & $\mathrm{Al}$ \\
\hline wt. \% & $6.5-7.5$ & 0.2 & 0.2 & 0.1 & $0.25-0.45$ & 0.1 & 0.2 & bal \\
\hline
\end{tabular}

Fig 2(b) illustrates the permanent metal mold, which is an ASTM B108-02 standard mold. Approximately $1.5 \mathrm{Kg}$ of A356 alloy is needed to fill the mold. Two tensile test bars are obtained from a casting. 


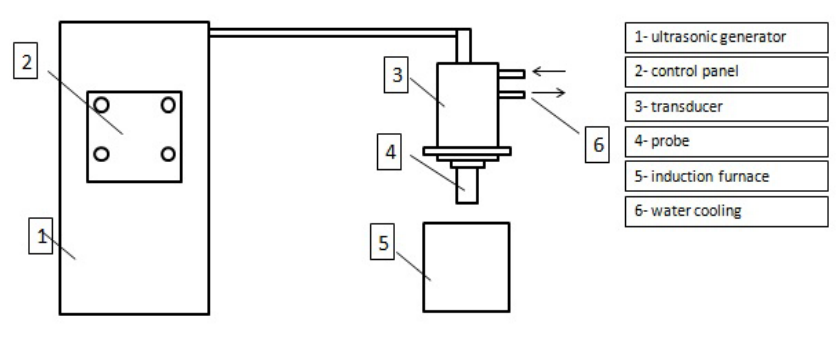

(a)

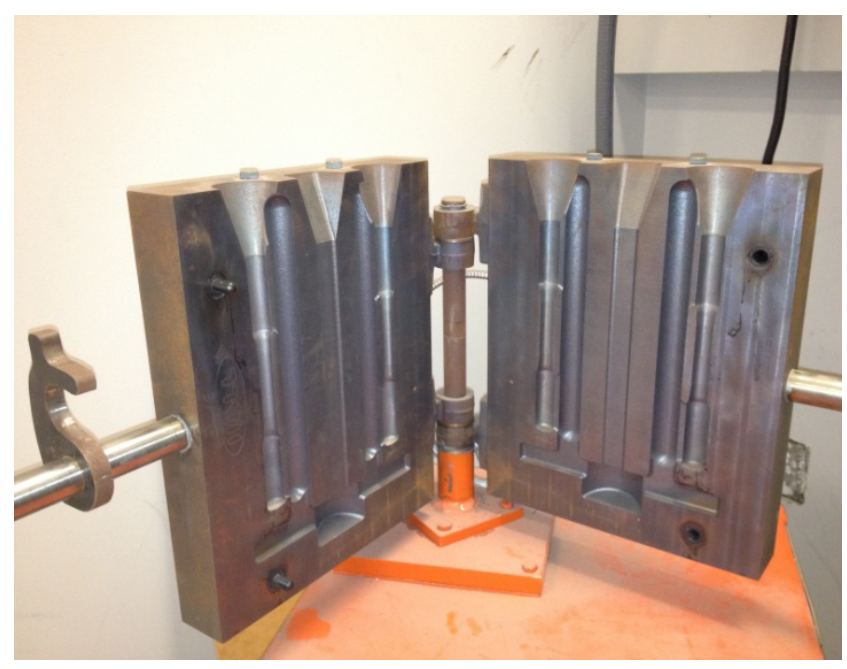

(b)

Figure 2. Equipment setup: (a) UST equipment and (b) permanent mold

For these experiments, at first, the furnace was heated up to $750{ }^{\circ} \mathrm{C}$ to melt the A356 ingot material. Then, the ultrasonic probe was inserted about $25 \mathrm{~mm}$ into the melt. A $1.75 \mathrm{~kW}$ power (about $70 \%$ of the maximum available power $2.4 \mathrm{~kW}$ ) was applied to the melt via an $\mathrm{Nb}$ probe for 15 minutes. The melt surface was protected by argon. The melt was then poured into a ladle which has a capacity of approximately $3 \mathrm{Kg}$ and then from the ladle to a permanent metal mold which was preheated to about $300{ }^{\circ} \mathrm{C}$. After cooling down, the mold was removed and samples were prepared for metallographic characterization.

The non-UST samples were obtained by Ar melt degassing at $750^{\circ} \mathrm{C}$ for 15 minutes, and then melt was poured into the permanent metal mold at $750^{\circ} \mathrm{C}$ (about $140{ }^{\circ} \mathrm{C}$ superheat).
In these experiments, four small samples from the same position of cast samples were prepared for metallographic characterization and four tensile test bars were made to determine the tensile properties.

\section{Results and Discussion}

Fig. 3(a) and (b) show the A356 as-cast microstructures without and with UST processing at the 200x magnification, while Fig. 3(c) and (d) show the same A356 as-cast microstructures at $1000 \mathrm{x}$ magnification. The samples without UST treatment have coarser microstructures than the ones with UST. It can be seen from Fig. $3 b$ that the dendrite structure is broken up because of the UST treatment. Basically, more equiaxed dendritic structure can be observed in the micrographs obtained via UST. When comparing Fig. 3(c) and 3(d), it can be seen that the $\mathrm{Si}$ eutectic structure (black area) is more modified. This is another important effect of UST. Ultrasonic treatment can reduce the size of eutectic silicon by an order of magnitude; the aspect ratio was also reduced by ultrasonic treatment [23].

Table 2 presents the measured SDAS (secondary dendrite arm spacing) and eutectic spacing. The SDAS and eutectic spacing were measured from the optical microscope pictures. According to Table 2, the samples with ultrasonic treatment have both the SDAS and the eutectic spacing decreased by $15-20 \%$.

Table 2. SDAS and eutectic spacing

\begin{tabular}{|c|c|c|c|c|}
\hline Mold samples & $\begin{array}{c}\text { SDAS } \\
\mu \mathrm{m}\end{array}$ & $\begin{array}{c}\text { Average } \\
\mu \mathrm{m}\end{array}$ & $\begin{array}{c}\text { Eutectic } \\
\text { spacing } \\
\mu \mathrm{m}\end{array}$ & $\begin{array}{c}\text { Average } \\
\mu \mathrm{m}\end{array}$ \\
\hline \multirow{3}{*}{ Without UST } & 26.5 & \multirow{3}{*}{28.9} & 1.8 & \multirow{3}{*}{2.1} \\
\hline & 26.9 & & 2.4 & \\
\hline & 33.4 & & 2.1 & \\
\hline \multirow{3}{*}{$15 \mathrm{~min}$ UST } & 19.8 & \multirow{3}{*}{24.7} & 1.5 & \multirow{3}{*}{1.7} \\
\hline & 23.0 & & 1.6 & \\
\hline & 31.4 & & 1.9 & \\
\hline
\end{tabular}

The decrease in eutectic spacing is usually due to high growth rates of these eutectic phases [24]. But because high power acoustic energy was injected into the melt, slower growth rate of the eutectic phases may occur. It can also be observed that the ultrasonic induced degassing is more efficient than argon degassing (see Fig. 3 and Ref. [25]). 


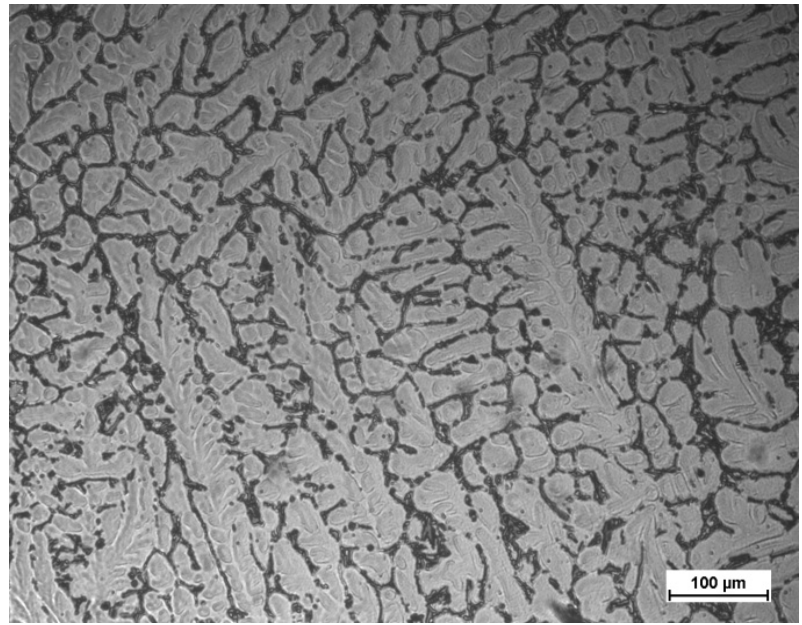

(a)

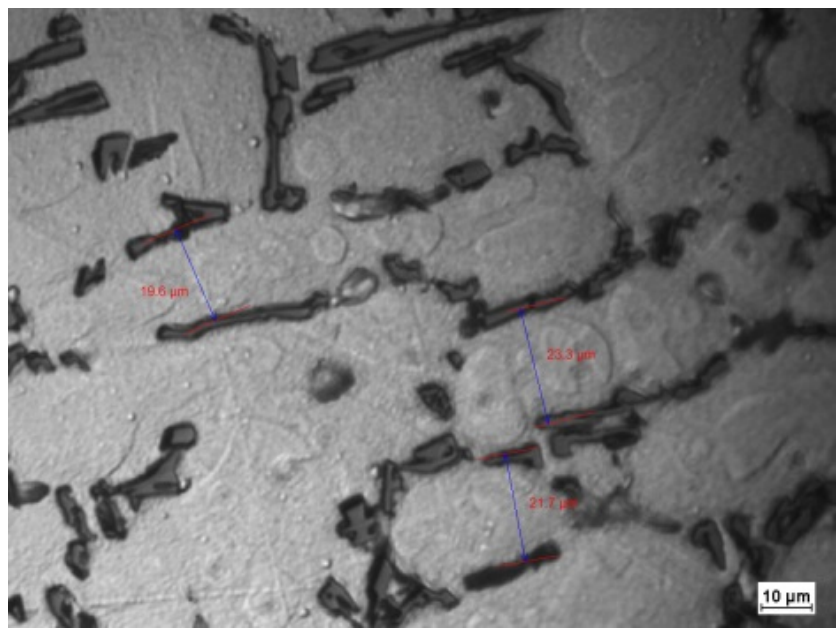

(c)

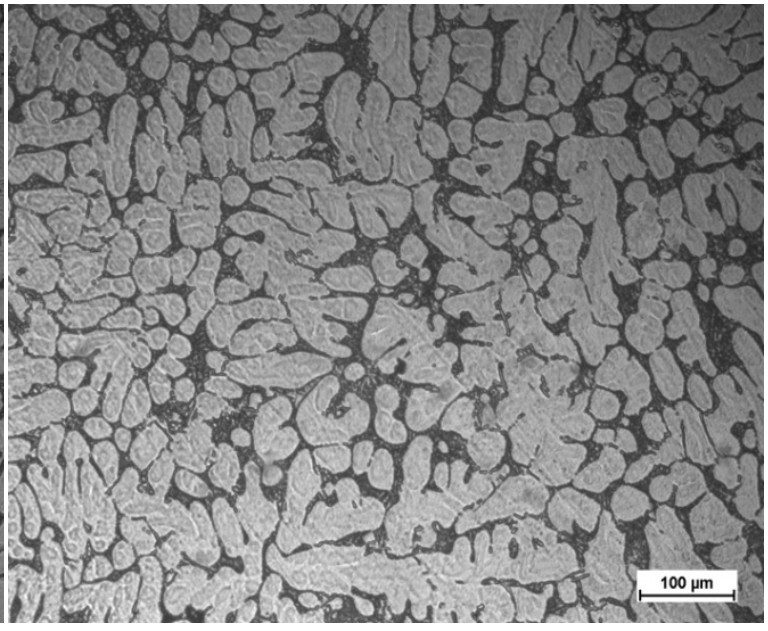

(b)

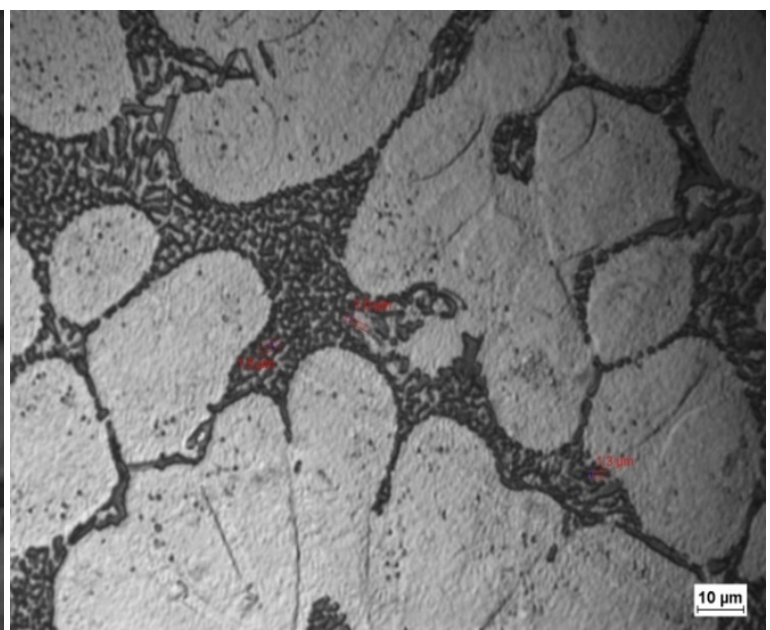

(d)

Figure 3. Micrographs of A356 permanent mold samples: (a) and (c) without UST; (b) and (d) with UST

Other phenomena that occur during ultrasonic processing of alloy may contribute to the refinement of the eutectic silicon phase. One phenomenon is the ultrasonic induced convection. The strong convection may enhance the heat transfer from the melt to the environment, which will definitely increase the cooling rate of the melt; and because of that, samples treated by UST may have higher eutectic growth rate. Acoustically induced convection can also affect nucleation of the silicon phases by altering the constitutional supercooling at the front of the growing eutectic grains [26]. Another phenomenon is the ultrasonic induced pressure oscillations in the liquid pools. Further research is still needed to determine the effect of this phenomenon on the growth of Si eutectic.

As shown in Table 3, after the T6 heat treatment, a mechanical testing was performed to evaluate tensile strength, yield strength and elongation. By using the UST treatment the tensile strength increased by at least $10 \%$ and the elongation levels by at least $20 \%$ in all studied samples when compared to the ones without the UST treatment.
Table 3. Tensile testing results

\begin{tabular}{|c|c|c|c|}
\hline $\begin{array}{c}\text { Permanent } \\
\text { mold samples }\end{array}$ & $\begin{array}{c}\text { Tensile } \\
\text { strength } \\
\mathrm{MPa}\end{array}$ & $\begin{array}{c}\text { Yield strength } \\
\mathrm{MPa}\end{array}$ & $\begin{array}{c}\text { Elongation } \\
\%\end{array}$ \\
\hline Without UST & $228 \pm 4$ & $180 \pm 3$ & $4.0 \pm 0.3$ \\
\hline With UST & $250 \pm 5$ & $190 \pm 3$ & $4.9 \pm 0.3$ \\
\hline
\end{tabular}

\section{Concluding Remarks and Future Work}

The experiments in this study show that the UST has significantly positive effects on casting components even for cast microstructures obtained at high superheat (about $\left.140{ }^{\circ} \mathrm{C}\right)$. The effects include microstructure refinement, eutectic modification, and high level of hydrogen degassing.

Future work will include casting experiments at low 
superheat (lower than $10{ }^{\circ} \mathrm{C}$ ) in the presence of UST using a specially designed two-zone furnace. Also, a parametric study will be performed to determine the effects of key ultrasonic parameters, such as power, depth of the ultrasonic probe into the melt, etc. In addition, a recently developed CFD multiscale model [27-33] that can simulate ultrasonic cavitation, acoustic streaming as well ad microstructure evolution during the solidification of castings will be further validated and then applied to optimize future UST-experiments at the University of Alabama, Solidification Laboratory.

\section{REFERENCES}

[1] D. K. Chernov, Nauka Metallakh, Moscow: Metallurgizdat, 563,1950

[2] G. I. Eskin, Effect of ultrasonic (cavitation) treatment of the melt on the microstructure evolution during solidification of aluminum alloy ingots, Zeitschrift fuer Metallkunde 93, 502-506, 2002.

[3] G. I., Eskin, Nedendritnaia kristallizaciia legkich splavov: itogi i perspektivy, Liteinoe proizvodstvo, 1-4, 94-104, 2005.

[4] G. I. Eskin, Ultrasonics Sonochemistry, Vol 8 No.3, 319, 2001.

[5] G. I. Eskin, Ultrasonics Sonochemistry, Vol 1 No.1, S59, 1994.

[6] L. D. Rozenberg, ed., Sources of High-Intensity Ultrasound, vols. 1-2, New York, Plenum Press, 1969.

[7] T. V. Atamanenko, D. G. Eskin, L. Katgerman, Structure refinement by means of (ultrasonic) cavitation melt treatment, Aluminium Cast House Technology, 2007.

[8] T. T. Meek, Q. Han, Ultrasonic Processing of Materials, U.S. Department of Energy, USA (accessed 9.01.2010), 2006.

[9] X. Jian, H. Xu., T.T. Meek, and Q. Han, Effect of Power Ultrasound on Solidification of Aluminum A356 Alloy, Materials Letters, vol. 59, issues 2-3, 190-193, 2006.

[10] G. I. Eskin, Ultrasonic Treatment of Light Alloys Melts, Amsterdam, Gordon and Breach Science Publisher, 334, 1998.

[11] O. V. Abramov, Ultrasound in Liquid and Solid Metals, Boca Raton, CRC Press, 493, 1994.

[12] G. I. Eskin, Principles of ultrasonic treatment: application for light alloys melts, Advanced Performance Materials 4, 223-232, 1997.

[13] G. I. Eskin, Influence of cavitation treatment of melts on the processes of nucleation and growth of crystals during solidification of ingots and castings from light alloys, Ultrasonics Sonochemistry, 1, 59-63, 1994.

[14] Southin, R.T. "The influence of low-frequency vibration on the nucleation of solidifying metals", Journal of the Institute of Metals 94, 401-407 (1966)

[15] J. Campbell, Effects of vibration during solidification", International Metals Reviews 26, 71-108, 1981.
[16] X. Jian, H. Xu, T. T. Meek, and Q. Han, Effect of power ultrasound on solidification of aluminium A356 alloy", Materials Letters 59, 190-193, 2005.

[17] B. Chalmers, Principles of Solidification, New York: John Wiley and Sons, 319, 1964.

[18] S. J. Blundell and K. M. Blundell, Concepts in Thermal Physics, Oxford, Oxford University Press, 464, 2006.

[19] S. L. Hem, The effect of ultrasonic vibrations on crystallization processes, Ultrasonics 5, 202-207, 1967.

[20] D. M. Stefanescu, Science and Engineering of Casting Solidification, New York, Springer, 2nd ed. ,2008.

[21] H. Yasuda,Y. Yamamoto, and N. Nakatsuka, In situ observation of nucleation, fragmentation and microstructure evolution in $\mathrm{Sn}-\mathrm{Bi}$ and $\mathrm{Al}-\mathrm{Cu}$ alloys, International Journal of Cast Metals Research, vol. 21, no. 1, 125-128, 2008.

[22] D. Ruvalcaba, R. H. Mathiesen, D. G. Eskin, L. Arnberg, and L. Katgerman, In situ observation of dendritic fragmentation due to local solute-enrichment during directional solidification of an aluminum alloy, Acta Materialia, 55, 4287-4292, 2007.

[23] X. Jian, T. T. Meek, Q. Han, Refinement of eutectic silicon phase of aluminum A356 alloy using high-intensity ultrasonic vibration, Scripta Materialia 54 893-896, 2006.

[24] S. C. Flood and J. D. Hunt, Modification of Al-Si eutectic alloys with Na, Met. Sci. 15, 287-294, 1981.

[25] H. Xu, X. Jian, T. T. Meek, and Q. Han, Degassing of molten aluminum A356 alloy using ultrasonic vibration, Materials Letters 58, 3669-3673, 2004.

[26] G. Heiberg, Ch. A. Gandin, H. Goerner, L. Arnberg, Experimental and modeling studies of the thermal conditions and magnesium, iron and copper content on the morphology of the aluminum silicon eutectic in hypoeutectic aluminium silicon alloys, Metall. mater. trans. 35A 2981-2991, 2004.

[27] L. Nastac, Mathematical modeling of the solidification microstructure evolution in the presence of ultrasonic stirring, Metallurgical and Materials Transactions B, Vol. 24, 1297-1305, 2011.

[28] L. Nastac, Multiscale Modeling of the solidification microstructure evolution in the presence of ultrasonic stirring”, IOP Conf. Ser.: Mater. Sci. Eng. 33 012079, 2012.

[29] L. Nastac, Numerical Modeling of Solidification Morphologies and Segregation Patterns in Cast Dendritic Alloys, Acta Materialia 47 (17):4253-4262, 1999.

[30] L. Nastac, Analytical Modeling of Solute Redistribution During the Initial Unsteady Unidirectional Solidification of Binary Dilute Alloys: Comparison with Experiments, Scripta Materialia, Vol. 39, No. 7, pp. 985-989, 1998.

[31] L. Nastac and D. M. Stefanescu, Computational Modeling of $\mathrm{NbC/Laves} \mathrm{Formation} \mathrm{in} \mathrm{Inconel} 718$ Equiaxed Castings, Metallurgical Transactions, Vol. 28A, pp. 1582-1587, 1997.

[32] L. Nastac, Modeling and Simulation of Microstructure Evolution in Solidifying Alloys, Springer, New York, 2004.

[33] L. Nastac, Influence of Gravitational Acceleration on Macrosegregation and Macrostructure during the Solidification of Directionally Cast Binary Alloys: A Numerical Investigation, Numerical Heat Transfer, Part A, Vol. 35, No. 2, pp. 173-189, 1999 